\title{
Designing of Microcontroller Based Home Appliances Governor Circuits
}

\author{
Mohammad Zeyad, Prodip Biswas, Md. Zakaria Iqbal, Susmita Ghosh*, Pronab Biswas \\ Faculty of Engineering, Electrical and Electronic Engineering, American International \\ University-Bangladesh (AIUB), 66/a Kuratoli, Kuril, Dhaka-1229, Bangladesh. \\ * Corresponding author. Tel.: +8801717373244; email: susmitaghosh14@aiub.edu \\ Manuscript submitted April 17, 2018; accepted June 14, 2018. \\ doi: 10.17706/ijcee.2018.10.2.94-105
}

\begin{abstract}
Automatic control of home appliances is highly demanded in all over the world. In this energy saving era, energy can be saved without hampering our day to day busy scheduled life if it gets utilization of automated remote load controlled devices. This paper illustrates wireless home appliances controlling circuit using microcontroller. This method proposes design of a system that will be able to control apparatus remotely and will likewise empower home security against interruption without property holder. Remote speed controller of a load is being incorporated in the system which is one of the most attractive features of the system. An accessible security system through an app is also merged with the speed controller which provides influential security to the loads from unexpected users. Finally, power and speed calculations are done to complete the research.
\end{abstract}

Key words: Arduino Uno, AT mega 328p, BT HC 06, SIM800 (GSM module), security control app (LED).

\section{Introduction}

Every Automation is expected to encourage the procedure or component for its operation and control information stockpiling and handling is an inner piece of any programmed control system. The need is to have a device 'microcontroller' which permits controlling the planning and succession of these machines and process advance with the assistance of the 'microcontroller'. Today we see many industrial and domestic products like remote controllers, telephone bill printing machines, automatic or semi-automatic washing machine automobiles etc. [1]. Presently, the utilization and advancement of considerably another remote correspondence system, microcontroller based systems have turned out to be constrained to remote control reason in various devices. Home Automation is undeniably a resource which can make a home environment automated. People can control their electrical devices via these home automation systems and set up controlling actions through Mobile. In future, this product may have a high potential for marketing.

However, the objective of this project is to implement a low cost, reliable and scalable home appliances system and create a microcontroller based system where the energy wastage can be reduced by using such kind of device which will control the ON/OFF timing of load and will also control the home electronic appliances from any-where, just using smart phone application. Finally, all features will be secured with accessible security system.

In the first section of the paper, the conventional method to design home appliances control system is described. Next, some useful flowcharts are added and simulations are done to justify the system procedure. 
Finally, different parameters such as output voltage, output current, power and speed (rpm) are analyzed for the different conditions of the load.

\section{Literature Review}

Smart home appliances are becoming popular due to its numerous benefits. In the recent years, smart home appliances are an essential requirement of house owner or households to keep home safe. The increasing interest in smart home technologies has created a need for a comprehensive literature survey. In this segment, we are going to describe the previous works about a smart home appliances system, along with related definitions, applications and information about the manufacturing of its components.

Although smart devices have been available in the past, their use has been restricted because they lack intercommunication. One suggested solution is to connect all smart devices using hard wiring [2]; however, the resulting portability problem then creates a demand for a wireless network capable of accommodating the devices. Organizations have therefore developed management, additional services, and gate-ways for smart devices [2].

Sougata Das et al., describes the design and development Home Automation System in which a system for household appliance control using cell phone through global system for mobile communication (GSM) technology. This system allows the user or home owner to monitor and control the home appliances via mobile phone set by sending commands in the form of SMS (short message service) messages and the system also provides current status of the home appliances. The proposed system makes use of wireless control hence can be effectively used in systems were unwired connections are desired [3]. Akanksha Singh: presented the paper on how to control home appliances, safety \& security system using GSM technology by using android application through android mobile phone. It can control the appliances even in the absence of android phone by sending a normal sms [4].

Md Mehrab Haque, present a system where the user controls the home light through a button [5]. Mr. N. D. Chhabile, describe a simple system that turn on light when it's dark and turn off when it's light by using Arduino [4].

V. A. Tangade, presents home appliance controlling using Bluetooth, where control of home appliances, like fan, light can control by using Simplest Bluetooth, Android Smartphone and Arduino [4]. Bulbul Bhaskar and R. Swarnalatha, presents smart home automation system using AVR microcontroller. This system incorporates with sensors, microcontroller and Bluetooth module to provide automation capability to various household activities. An AVR microcontroller offers high performance and flexibility for controlling various appliances. This system can monitor the changes in temperature, lighting, detect fire and keep a check on the safety of the house [6].

\section{Design Prototype}

A microcontroller is a self-contained system with peripherals, memory and a processor that can be used as an embedded system [7]. Most programmable microcontrollers that are used today are embedded in other consumer products or machinery including phones, peripherals, automobiles and household appliances for automated systems. Due to that, another name for a microcontroller is "embedded controller". By using microcontroller transmitting \& receiving functions can be done easily \& accurately, that's why microcontroller based technology like Arduino \& SIM800 is used in this project. To accomplish our project goal, we control electrical loads by using GSM network and Bluetooth technology.

As this project is a home automated system, a prototype has been implemented where a demo house is being represented along with some loads like light and fan. Microcontroller is the most demanded programmable chip which is used for designing a home automated system. To complete this hardware 
design, 3 microcontrollers have been used. An adapter of $5 \mathrm{v}, 1 \mathrm{~A}$ rating is used for the conversion of $220 \mathrm{~V} \mathrm{AC}$ to $5 \mathrm{~V}$ DC which is the appropriate voltage for a microcontroller. A buck converter has been used because initially some unexpected negative polarity was present in the circuit. This buck converter is responsible for the reduction of some voltage of the microcontroller as well.

The Fig. 1 shows the block diagram of the entire system. In this figure, the microcontroller is represented by "MCU", Bluetooth HC-06s which are the slave modules, require an ace gadget to make an association is denoted by "BT" [8] and the SIM800 is represented by "GSM" which is an entire Quad-band GSM/GPRS arrangement in an SMT sort that can be inserted in the client applications [9].

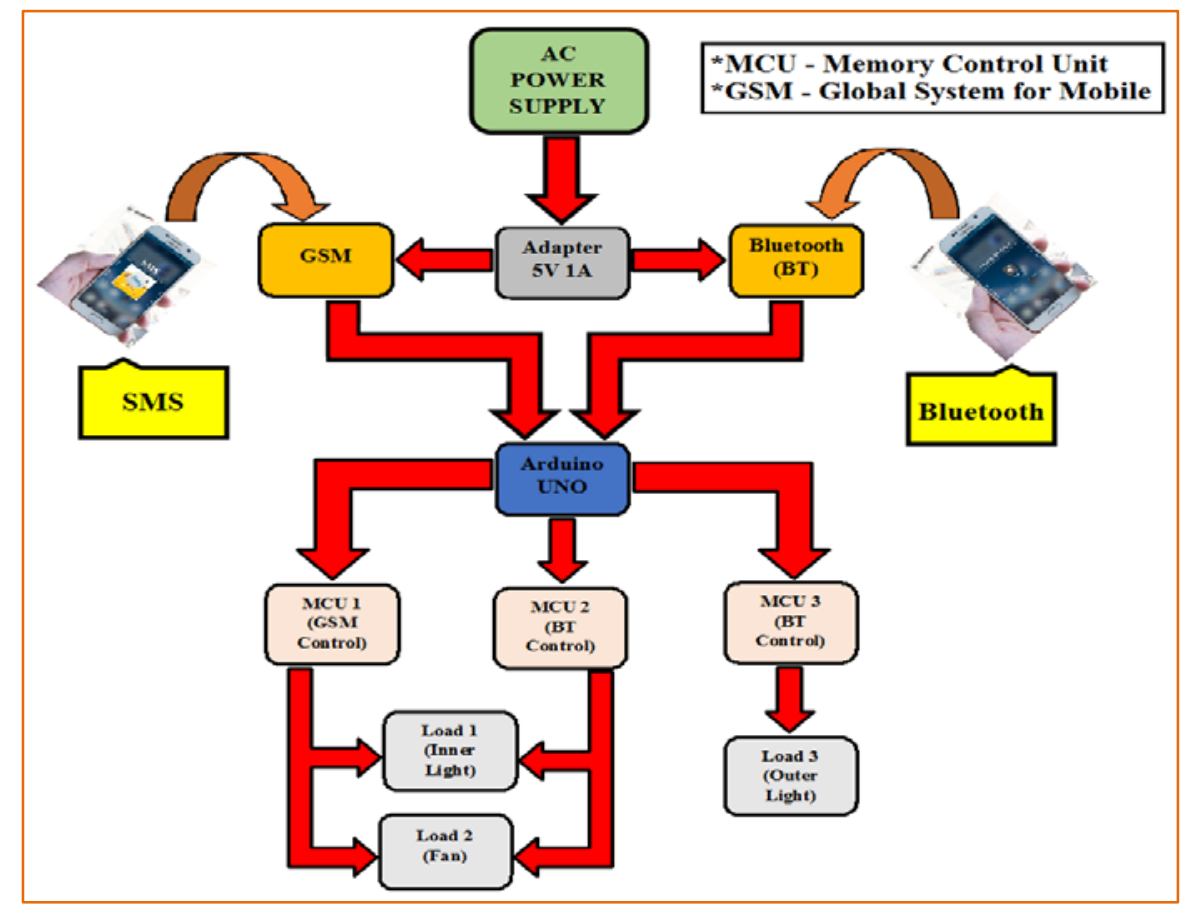

Fig. 1. Block diagram of the entire system.

Fig. 2 shows (a) OFF mode \& (b) ON mode of the complete system design. The Arduino Uno was connected to PC/Laptop, then the code was uploaded in microcontroller. Finally, a command sent to control loads by using following circuit diagram. By using $5 \mathrm{~V}$ signal sent from Arduino, the microcontroller act as a switch to turn ON/OFF the loads.

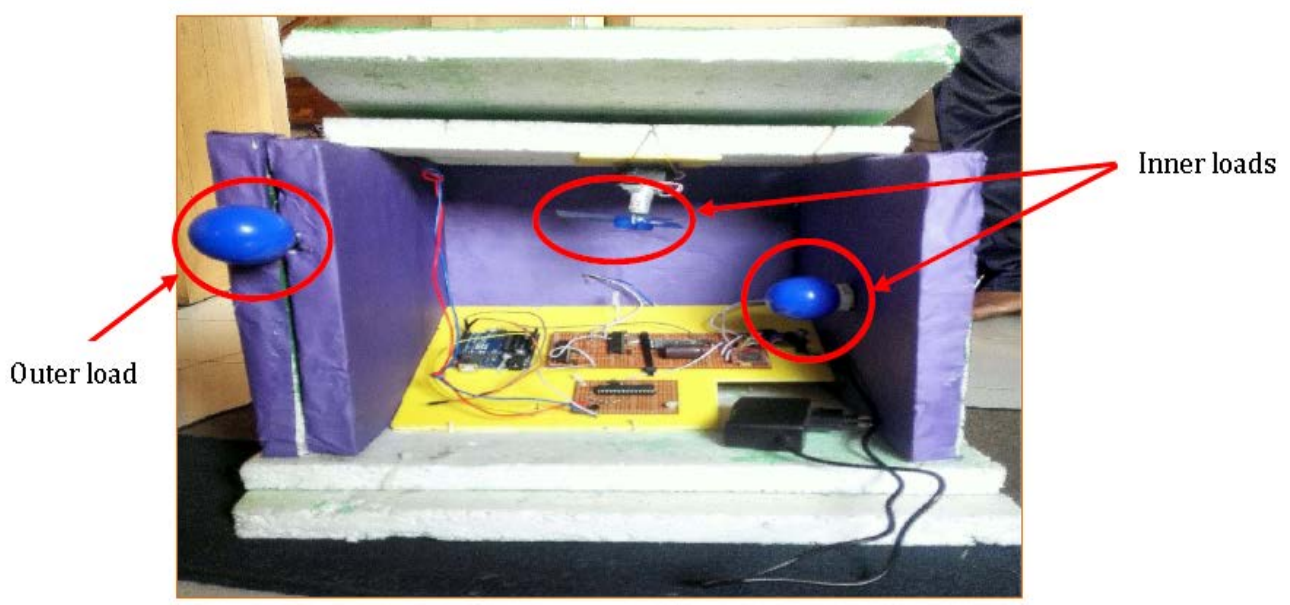

(a) Loads are in OFF mode 


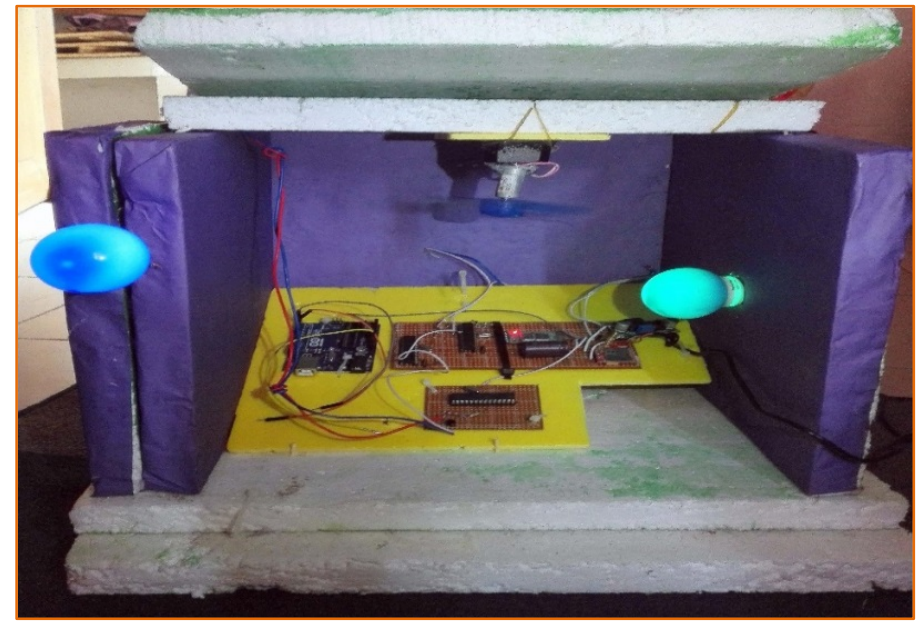

(b) Loads are in ON mode

Fig. 2. Complete system design.

\subsection{Timing Control of the Outer Load}

Fig. 3 shows the system design for controlling ON/OFF timing of outer load. To control the ON/OFF timing of outer load, firstly we load the programmable Arduino based code in a microcontroller. The advantage of using the programmable code is- user can control the load by setting any convenient time.

The other significant part of this outer load- user can control it in a decent range by using Bluetooth technology.

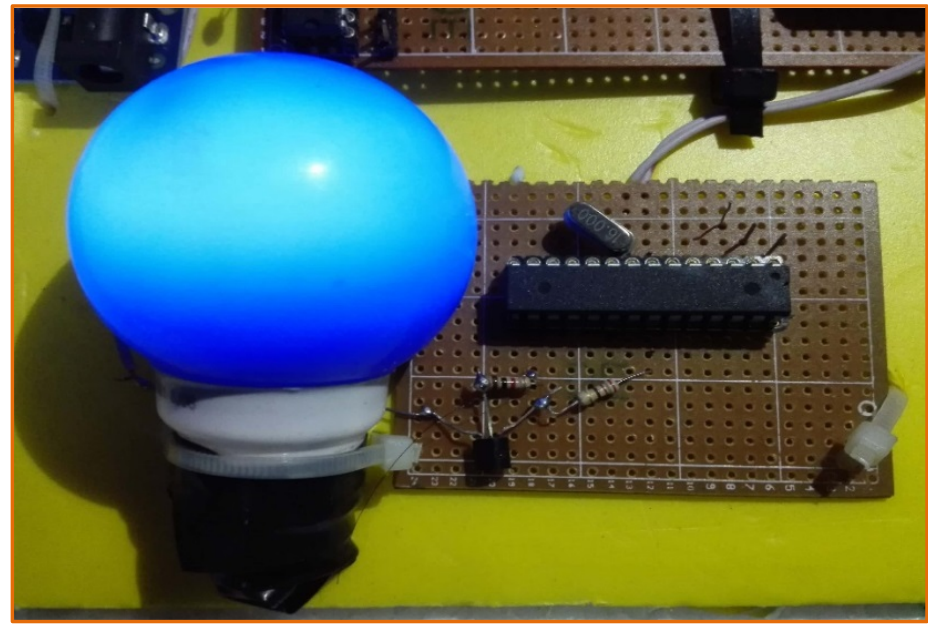

Fig. 3. System design of the ON/OFF timer circuit of outer load (ON mode).

\subsection{Inner Load Control Using GSM Module}

Fig. 4 shows the system design using GSM module. To operate the inner load (light, fan) of home, we used some accessible keywords which will help the user to access the GSM-based system by sending SMS from anywhere.

On the other hand, different keywords can be used for different users personally which is also secured the system with non-observant peoples.

Accessible keywords are:

$>$ \#abc1 --- Light ON

$>\quad \#$ abc0 --- Light OFF 
$>\quad$ \#abc3 --- Fan ON

$>\quad$ \#abc2 --- Fan OFF

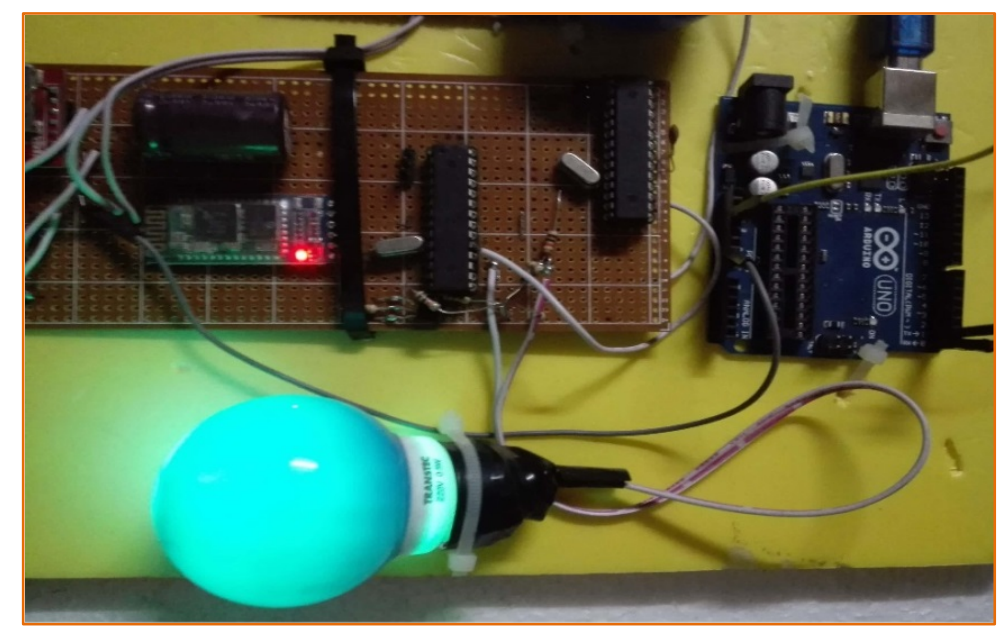

Fig. 4. System design of the GSM based load control circuit (ON mode).

\subsection{Inner Load Control Using Bluetooth Technology}

Fig. 5 shows the system design using Bluetooth. In this section load control is done using mobile app i.e. load control is possible from remote distance and without using switch.

The most attractive feature of our project is that in this system fan speed can also be controlled via mobile app and without using manual fan speed regulator.

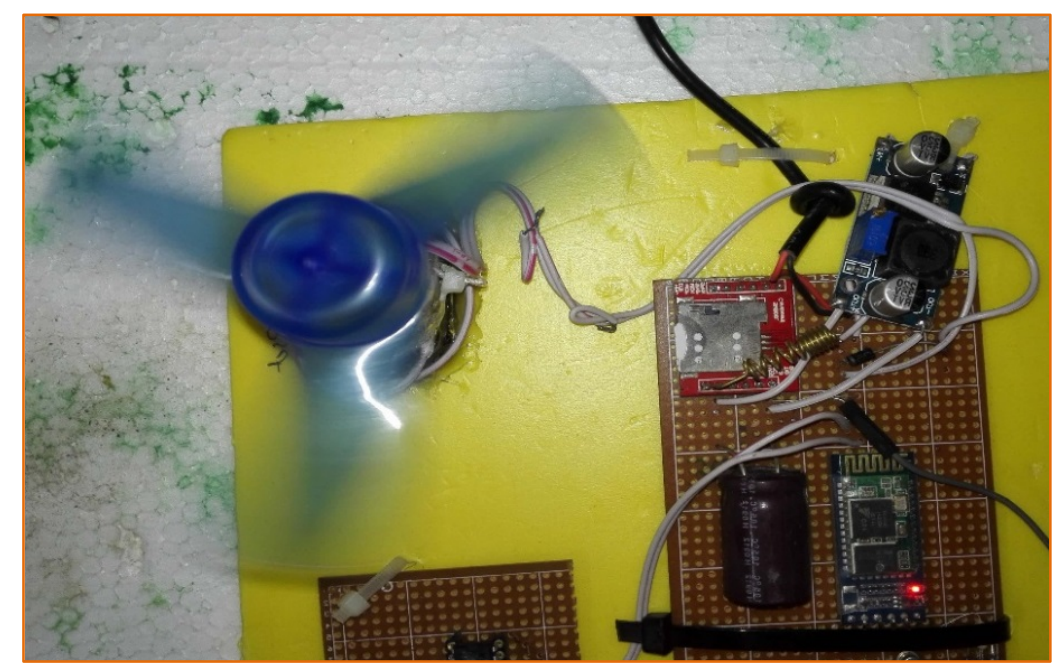

Fig. 5. System design of the Bluetooth based load control circuit (ON mode).

\subsection{Design of Security Control App- "LED”}

To improve system's security an accessible security system has been developed which works through an app that provides influential security which will help to secure the home appliances from unexpected users. The name of the security app is given as "LED".

To access this app, firstly, it is needed to connect with Bluetooth. Then the app asks to give a password. The user must choose a password of his own will. After entering the password, the app is ready to use. Fig. 6 shows the user manual of the security app. 

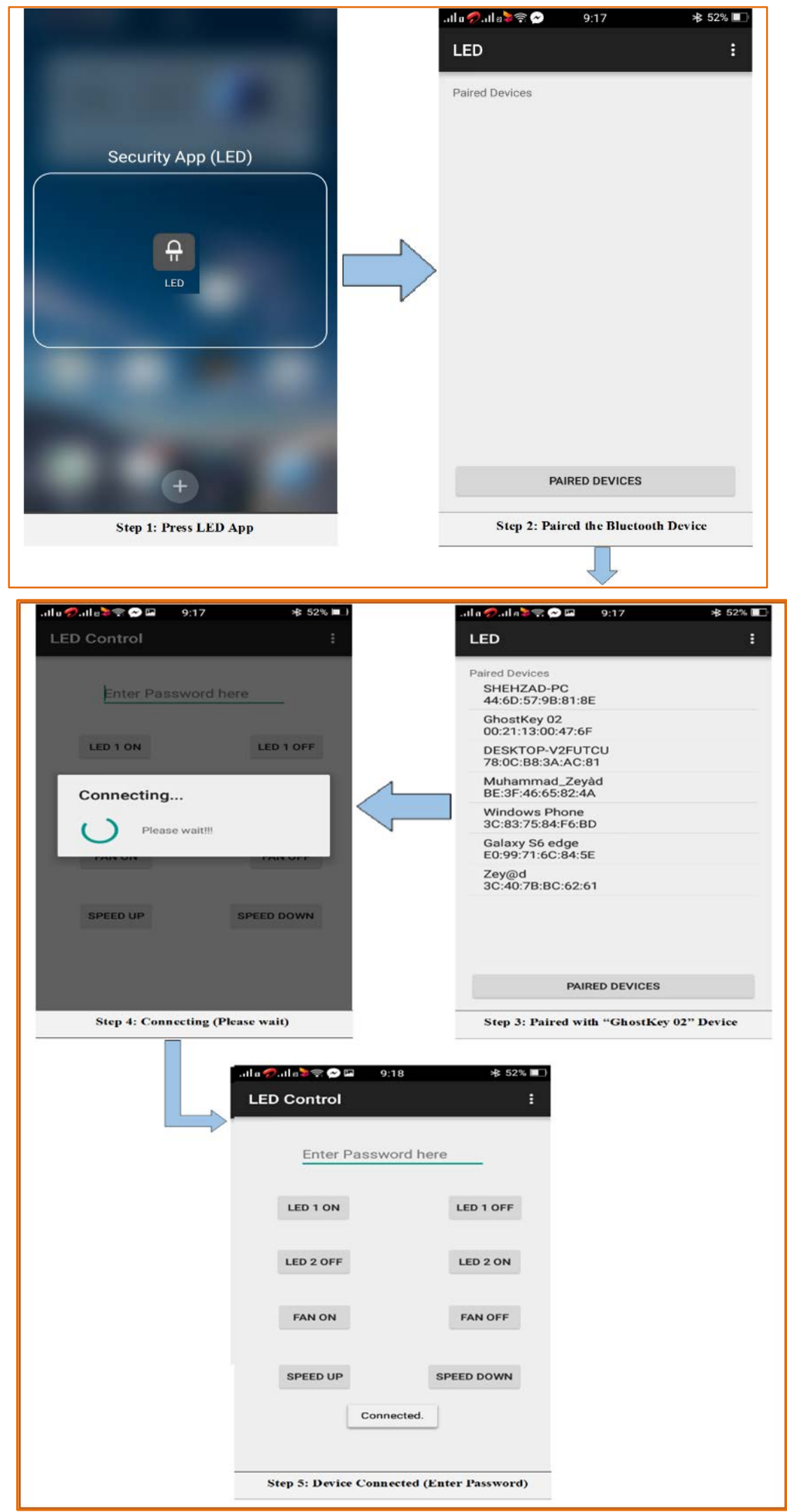

Fig. 6. User manual of the app.

\section{Simulations}

To complete the project successfully, software simulation is also necessary alongside with hardware 
implementation. For simulation Arduino and Proteus Professional 8.0 have been used.

Fig. 7 shows (a) the flow chart \& (b) the complete system design by using Proteus Professional 8.0.

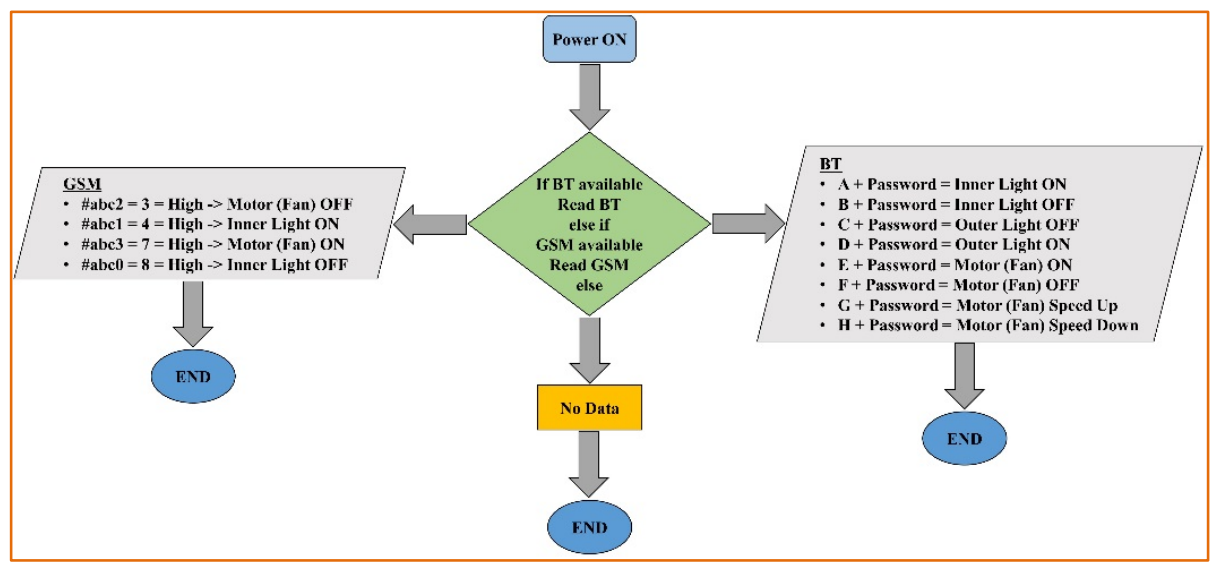

(a) Flow chart

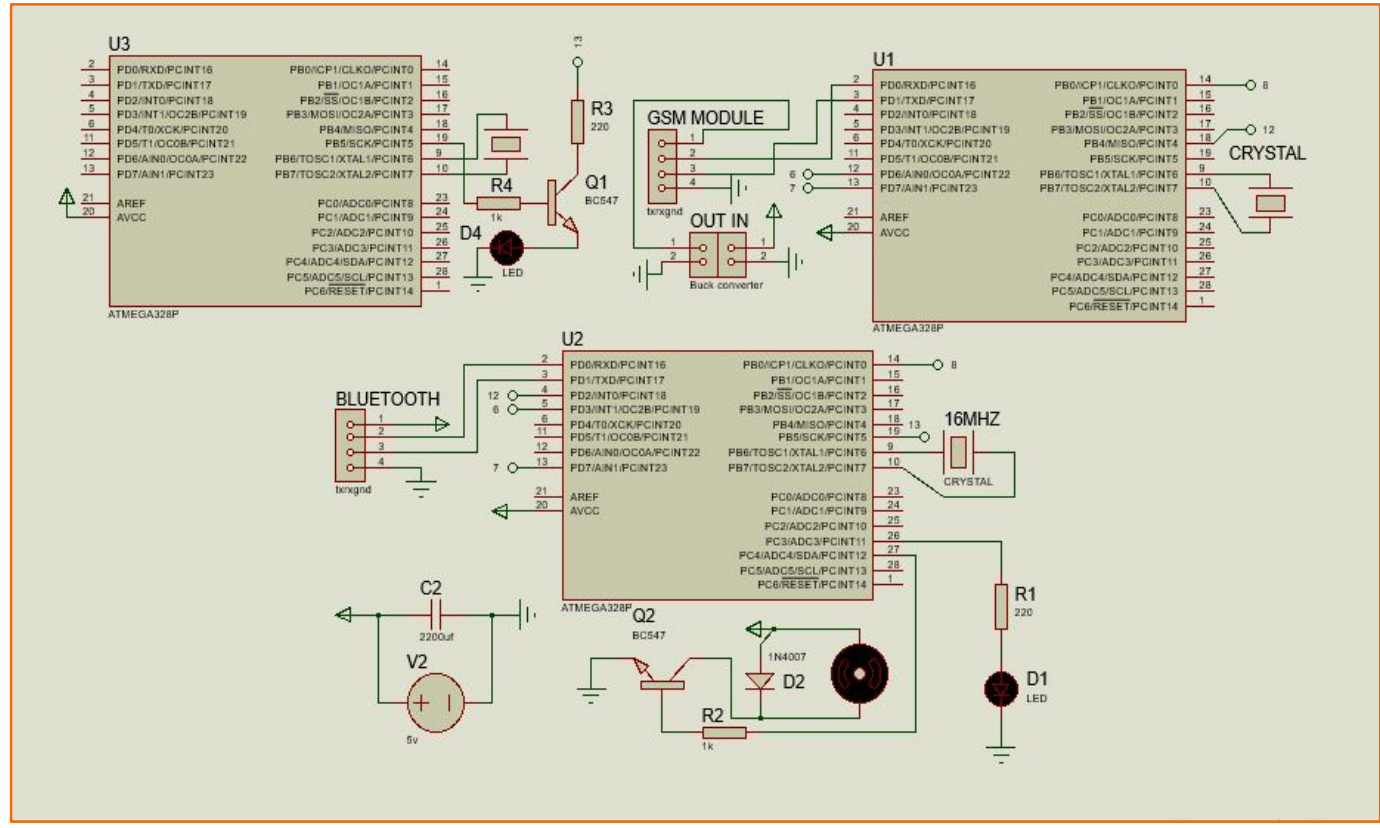

(b) Proteus simulation

Fig. 7. Simulation of complete system design.

Fig. 8 shows (a) the flow chart \& (b) the system design of ON/OFF timing of outer load by using Proteus Professional 8.0.

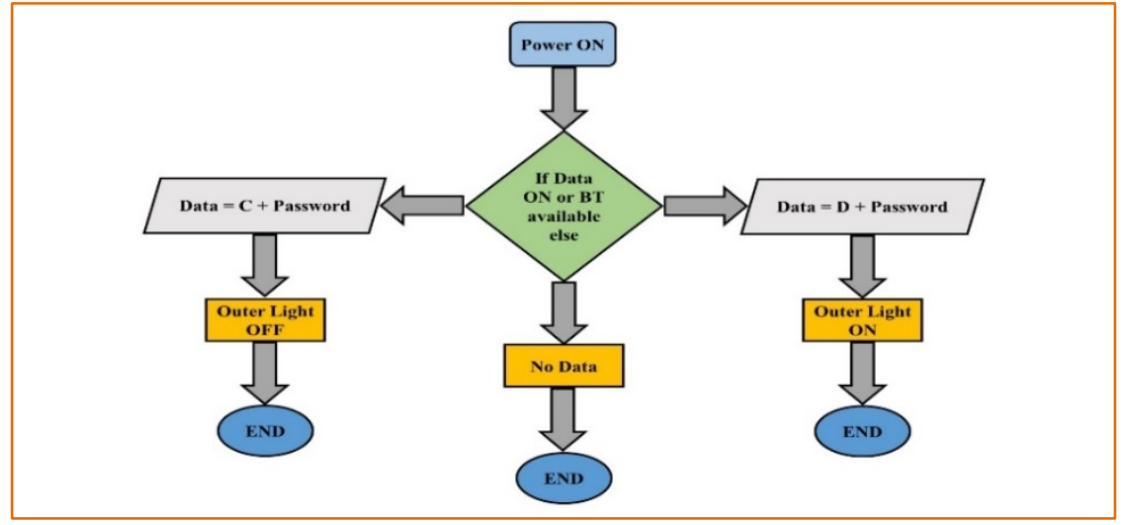

(a) Flow chart 


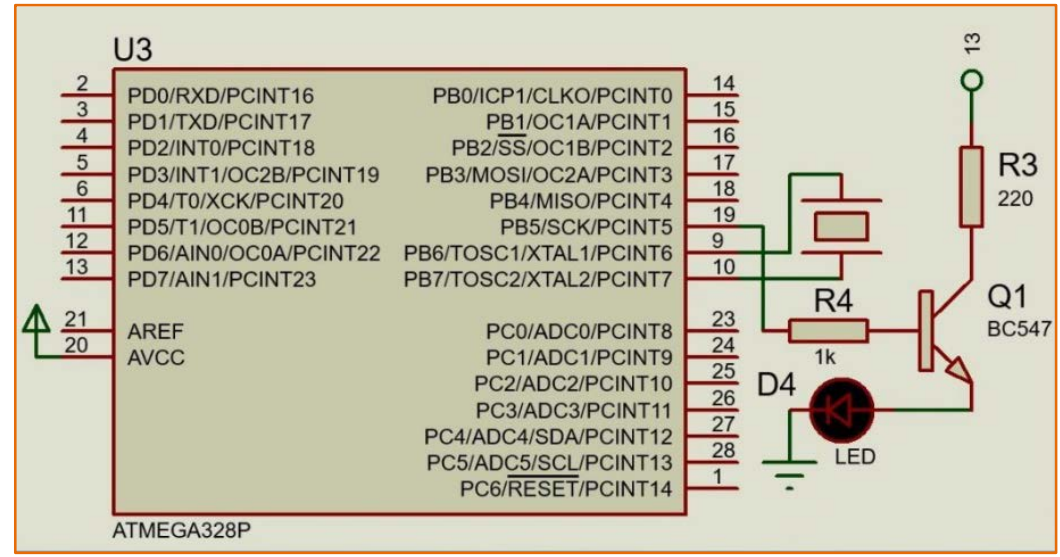

(b) Proteus simulation

Fig. 8. Simulation of ON/OFF timer circuit of outer load.

Fig. 9 shows (a) the flow chart \& (b) the system design of GSM based controlling load by using Proteus Professional 8.0.

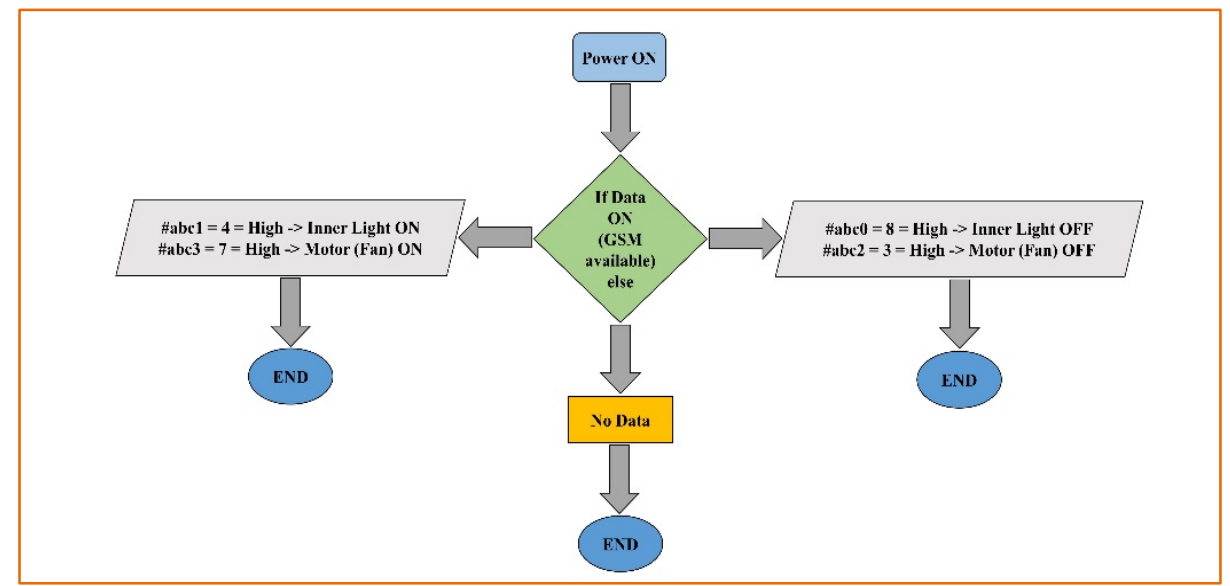

(a) Flow chart

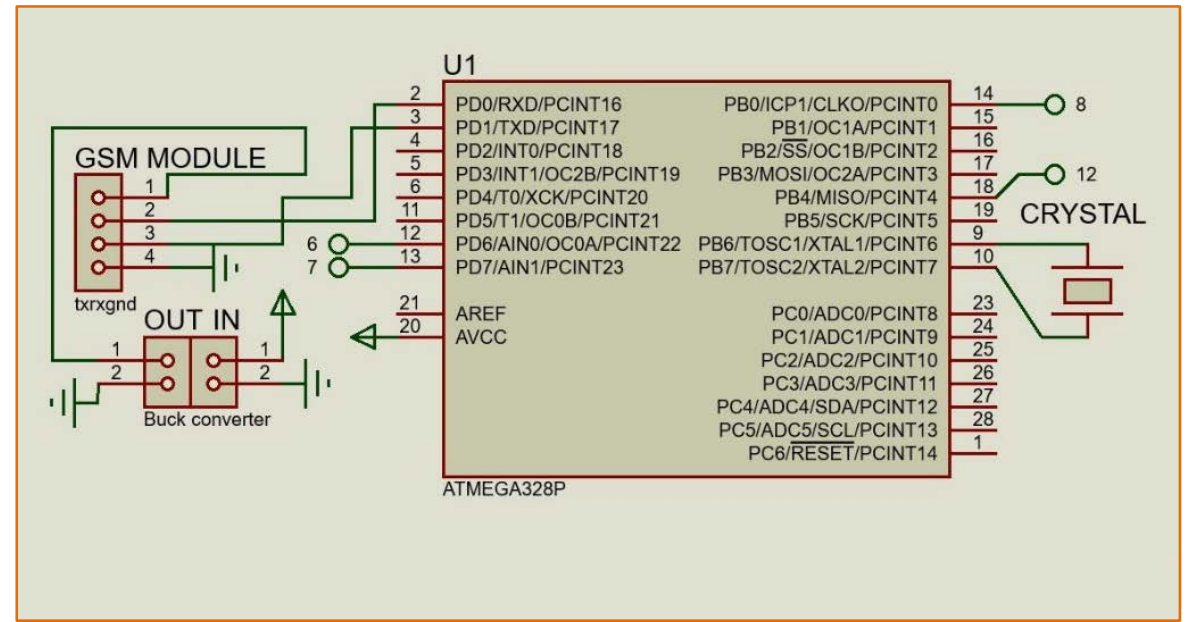

(b) Proteus simulation

Fig. 9. Simulation of GSM based load control circuit.

Fig. 10 shows (a) the flow chart \& (b) the system design of Bluetooth based controlling load by using Proteus Professional 8.0. 


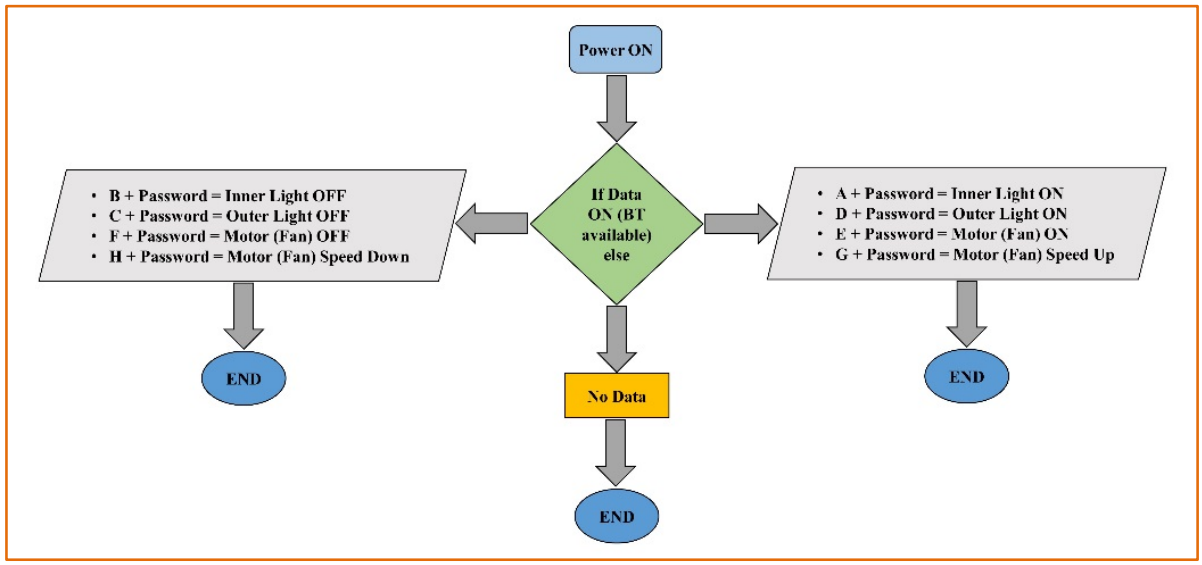

(a) Flow chart

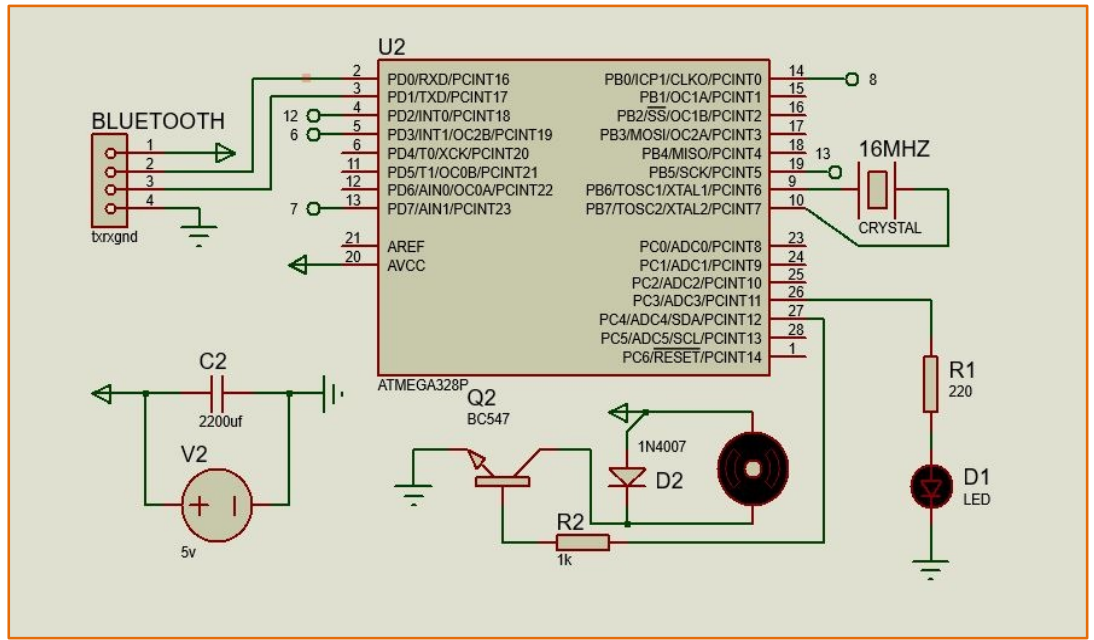

(b) Proteus simulation

Fig. 10. Simulation of Bluetooth based load control circuit.

\section{Results}

Table 1. Variation of Fan Speed

\begin{tabular}{cc}
\hline \hline Increasing steps & Speed (rpm) \\
\hline Condition 1 (Reference) & 150 \\
Condition 2 (UP) & 170 \\
Condition 3 (UP) & 190 \\
Condition 4 (UP) & 210 \\
Condition 5 (UP) & 230 \\
Condition 6 (UP) & 250 \\
\hline Decreasing steps & Speed (rpm) \\
\hline Condition 1 (Reference) & 150 \\
Condition 2 (DOWN) & 110 \\
Condition 3 (DOWN) & 90 \\
Condition 4 (DOWN) & 70 \\
Condition 5 (DOWN) & 50 \\
Condition 6 (DOWN) & 30 \\
Condition 7 (DOWN) & 10 \\
Condition 8 (DOWN) & 0 \\
OFF Condition &
\end{tabular}


Table 2. Measurement of Inner Load (Fan)

\begin{tabular}{cccc}
\hline $\begin{array}{c}\text { Fan Speed, } \mathbf{N} \\
\text { (rpm) }\end{array}$ & $\begin{array}{c}\text { Voltage, } \mathbf{V} \\
\text { (V) }\end{array}$ & $\begin{array}{c}\text { Current, I } \\
\text { (A) }\end{array}$ & $\begin{array}{c}\text { Power, } \mathbf{P} \\
\text { (W) }\end{array}$ \\
\hline 10 & 0.95 & 0.97 & 0.92 \\
70 & 1.20 & 0.97 & 1.16 \\
110 & 1.45 & 0.97 & 1.41 \\
130 & 1.63 & 0.97 & 1.58 \\
150 & 1.89 & 0.97 & 2.80 \\
170 & 2.04 & 0.97 & 1.98 \\
210 & 2.24 & 0.97 & 2.17 \\
250 & 2.89 & 0.97 & 2.80 \\
\hline \hline & & & \\
& Table 3. Measurement of Inner Load (Light) & \\
\hline \hline Load & Voltage, V & Current, I & Power, P \\
& (V) & (A) & 2.57 \\
\hline Inner Light & 2.71 & 0.95 & 2.50 \\
Outer Light & 2.69 & 0.93 &
\end{tabular}

In the working condition of the device, loads (light, fan) are gained voltage and current. By using a Multimeter, voltage \& current for different circumstances were measured. After finding voltage \& current values power of load (light) had been calculated by using P = VI. By using hand tachometer, the fan speed (rpm) was calculated for different regulated stages. Table 1, Table 2 and Table 3 represent the outcome of the project.

\section{Conclusion}

In this paper it has been shown that how a low-cost, reliable home appliance controlling circuit can be implemented where the controlling is possible anywhere within the GSM coverage area. To implement this project, three microcontrollers are utilized as a plat-form and low-cost loads are used. Main vision of the project is to control those loads by Bluetooth which has been achieved. Controlling of load is very easy and can be done remotely so there is no need of expert person to operate the system. Further modifications are possible in the circuit and some improvements can be done to make the system cheaper. The whole project is done following the Android operating system but it is possible to implement the whole project in iOS and Windows operating system. If this system can be implemented in a larger field like universities, restaurants, hotels, industries, garments and many more then it will be able to help the whole economic situation in a developing country like Bangladesh. Precisely, it will reduce human efforts and save some valuable time. This project has considerably more scopes for further research and development in near future. So, it is expected that more work will be done in near future to enhance its execution and make it more comfortable and friendly to the user.

\section{References}

[1] Rye, D. (1999, October). My life at X10. AV and Automation Industry eMagazine.

[2] Chen, C. Y., Tsoul, Y. P., Liao, S. C., \& Lin, C. T. (2009). Implementing the design of smart home and achieving energy conservation. Proceedings of the 7th IEEE International Conference on Industrial Informatics (INDIN 2009) (pp. 273-276). Cardiff, Wales, 23-26 June.

[3] Das, S., Debabhuti, N., Das, R., Dutta, S. \& Ghosh, A. (2014, Feb). Embedded system for home automation using SMS. Proceedings of the IEEE International Conference on Automation, Control, Energy and Systems (ACES) (pp. 1-6).

[4] Pandhare, R. B., Chhabile, N. D., Shengar, M. S., \& Tangade, V. A. (2017, April 09th). A review of home 
automation and security using arduino, bluetooth and GSM technology. International Journal of Research in Advent Technology (IJRAT), Special Issue National Conference (CONVERGENCE 2017).

[5] ON off led with 1 button. (2017, November 28). Retrieved from the website: http://www.instructables.com/id/On-Off-LED-With-1-Button

[6] Bhaskar, B., \& Swarnalatha, R. (2015, February). Smart home automation system using AVR microcontroller. International Journal of Advanced Technology in Engineering and Science, 3(2), 234-342.

[7] Delgado, A. R., Picking, R., \& Grout, V. (2006, July 11-14). Remote-controlled home automation systems with different network technologies. Proceedings of the 6th International Network Conference (INC 2006) (pp. 357-366).

[8] Potamitis, I., Georgila, K., Fakotakis, N., \& Kokkinakis, G. (2003, Sept. 1-4). An integrated system for smart-home control of appliances based on remote speech interaction. Proceedings of EUROSPEECH 2003, 8th European Conference on Speech Communication and Technology (pp. 2197-2200). Geneva, Switzerland.

[9] Jawarkar, N. P., Ahmed, V., Ladhake, S. A., \& Thakare, R. D. Micro-controller based remote monitoring using mobile through spoken commands. Journal of Networks, 3(2), 58-63.

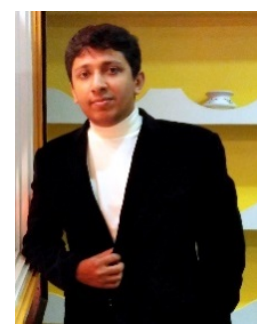

Mohammad Zeyad received his BSc in electrical and electronic engineering degree from American International University-Bangladesh in 2017 with a concentration in the field of power electronics. His area of interest is in power electronics engineering and biomedical engineering, wireless communication, microcontroller based system, signal processing etc.

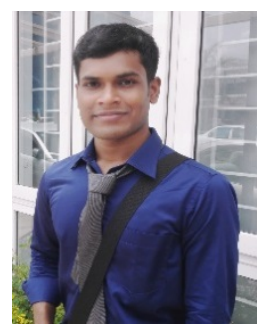

Prodip Biswas received his BSc in electrical and electronic engineering degree from American International University-Bangladesh in 2017 with a concentration in the field of power electronics. His research interests are in the field of power engineering, wireless communication, renewable energy, smart transportation system etc.

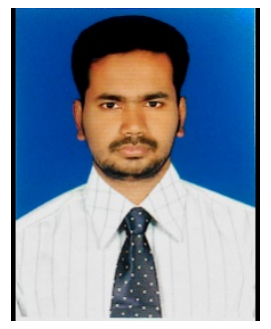

Md. Zakaria Iqbal received his BSc in electrical and electronic engineering degree from American International University-Bangladesh in 2017 with a concentration in the field of power electronics. His research interests are in the field of power engineering, wireless communication, robotics, smart transportation system etc.

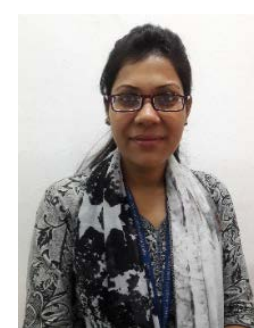

Susmita Ghosh obtained her BSc degree in EEE (2011) and MEng degree in MTEL (2013), Faculty of Engineering from American International University-Bangladesh (AIUB). Currently she is working as assistant professor in AIUB under the department of EEE, Faculty of Engineering. Her research interests are in the field of power system analysis, renewable energy, smart transportation system. 
Pronab Biswas received his BSc in electrical and electronic engineering degree from American International University-Bangladesh in 2017 with a concentration in the field of power electronics. His research interests are in the field of power electronics, electronics, wireless communication, smart transportation system etc. 